\title{
PEMODELAN MATEMATIK KANDUNGAN AIR \\ PADA PENGERINGAN APEL
}

\author{
Puguh Setyopratomo \\ Jurusan Teknik Kimia, Fakultas Teknik - Universitas Surabaya \\ Telp.(031)298-1158 Fax. (031)2981178 \\ E-mail : puguh@ubaya.ac.id
}

\begin{abstract}
Drying is one of the most significant method in food preservation. This study was conducted to investigate mathematical models of thin layer drying of apple slices. The kinetic of thin layer drying of apple slices was experimentally investigated in a hot air convective dryer. Crank solution for difusion in slab model and Lewis model for drying in thin layer were used to predict the drying profile. Drying characteristic of apple slices were determined using ambient air at $50^{\circ} \mathrm{C}$ and $0,4167 \mathrm{~m} / \mathrm{s}$ linier velocity. The result showed that Lewis model was more convenient for short-period drying, whereas the Crank solution model was more appropiate for long-periode drying.
\end{abstract}

Key words: apple, drying, mathematical model

\section{PENDAHULUAN}

Apel merupakan satu diantara jenis buah yang mempunyai nilai ekonomi tinggi. Apel dikonsumsi dalam berbagai bentuk seperti sebagai buah segar, jus atau potongan apel tipis kering (Wang et al., 2007).

Pengeringan, yang merupakan proses yang komplek yang melibatkan phenomena perpindahan massa dan panas dan banyak digunakan dalam industri pengolahan pangan (Cohen and Yang, 1995), sering menjadi proses utama dan merupakan tahanp yang paling mahal dari serangkaian tahap pengolahan pasca panen. Proses pengeringan akan memperbaiki daya tahan (shelf life) produk tanpa penambahan bahan kimia pengawet dan mengurangi volume produk maupun biaya transportasi. Buah segar umumnya mempunyai kadar air yang tinggi, sehingga mengakomodasi tingginya aktivitas metabolik. Aktivitas metabolik ini berlangsung terus pada masa pasca panen yang menjadikan buah pada umumnya cepat membusuk (Atungulu et al., 2004). Pemodelan matematik dan simulasi terhadap kurva pengeringan pada berbagai kondisi operasi sangat penting untuk mencapai pengendalian yang lebih baik selama proses pengeringan skala komersial dan juga dapat digunakan untuk meningkatkan perbaikan menyeluruh terhadap kualitas produk akhir. Beberapa model sering digunakan untuk mempelajari pengaruh variabel-variabel yang digunakan dalam proses, memprediksi kinetika pengeringan produk dan mengoptimumkan parameter-parameter dan kondisi operasi (Karathanos and Belessiotis, 1999). 
Dalam proses pengeringan bahan dikenal dua periode laju pengeringan, yaitu pengeringan periode laju konstan dan periode laju menurun. Pengeringan periode laju konstan berlangsung sampai mencapai kadar air tertentu yang disebut dengan kadar air kritik. Pengeringan bahan yang dilakukan dibawah kadar air kritiknya merupakan pengeringan periode laju menurun. Adapun kadar air terendah yang dapat dicapai untuk setiap proses pengeringan disebut kadar air kesetimbangan. Besarnya kadar air kesetimbangan bahan ditentukan oleh jenis bahan, suhu dan humiditas medium pengeringnya.

Proses pengeringan bahan pangan umumnya berlangsung pada periode laju pengeringan menurun (Wang and Brennan, 1992). Persamaan model pengeringan lapis tipis digunakan untuk mengestimasi waktu pengeringan beberapa produk dan juga digunakan untuk mengkonstruksi prediksi kurva pengeringan.

Tujuan dari penelitian ini adalah untuk mendapatkan kurva pengeringan yang dikembangkan dari model pengeringan lapis tipis dan kemudian membandingkan dengan kurva pengeringan dari data percobaan.

Pada proses pengeringan, umumnya berlangsung empat mekanisme transfer (S. Mounir \& K. Allaf, 2009), yaitu: 1) perpindahan panas dari sumber panas (outside) ke permukaan bahan, dimana energi dipindahkan dengan kontak, konveksi atau radiasi; 2) perpindahan panas dalam bahan, energi dipindahkan secara konduksi; 3) perpindahan air dalam bahan, berlangsung baik dalam bentuk cairan (dengan berbagai mekanisme mencakup kapilaritas dan difusì molekuler, dimana gaya penggeraknya berupa gradien kadar air) dan/atau berupa gas (gaya penggeraknya gradien tekanan parsial uap air); 4) perpindahan uap air dari permukaan bahan ke bulk (outside).

Untuk bahan-bahan yang berasal dari produk-produk pertanian dan perkebunan, perpindahan panas ke permukaan bahan pada saat kandungan air dalam bahan tinggi menghasilkan pengeringan periode konstan dan peristiwa ini terjadi dalam waktu yang sangat singkat, sehingga praktis keseluruhan proses pengeringan berlangsung dengan laju menurun.

Dalam hal pengeringan secara konveksi dengan udara panas dengan laju alir dan suhu udara yang mencukupi dapat diasumsikan perpindahan panas dan massa yang terjadi di luar bahan (eksternal) tidak mempengaruhi perpidahan massa secara keseluruhan, sehingga hanya perpindahan panas dan massa yang terjadi dalam bahan (internal) yang dianggap mengendalikan keseluruhan proses (S. Mounir, 2007). Mounir \& Allaf (S. Mounir \& K. Allaf, 2007) mengasumsikan bahwa ketika perpindahan massa jauh lebih lambat dari perpindahan panas konduksi dalam bahan, maka kinetika pengeringan dikendalikan oleh perpindahan massa dalam bahan, dan hal ini secara umum terjadi pada pengeringan bahan-bahan biopolimer. Dalam kasus ini formulasi 
Allaf (K. Allaf, 1982) umumnya

digunakan, yaitu :

$$
\frac{\rho_{w}}{\rho_{m}}\left(\bar{v}_{w}-\vec{v}_{m}\right)=-D_{e f f} \operatorname{gr} a d \frac{\rho_{w}}{\rho_{m}}
$$

dimana:

$\rho_{w}$ : apparent density dari air dalam bahan $\left(\mathrm{kg} \cdot \mathrm{m}^{-3}\right)$,

$\rho_{m}$ : apparent density dari bahan kering $\left(\mathrm{kg} \cdot \mathrm{m}^{-3}\right)$,

$v_{w}$ : kecepatan absolut air mengalir dalam bahan berpori $\left(\mathrm{m}^{-1} \mathrm{~s}^{-1}\right.$.

$v_{m}:$ kecepatan absolut dari bahan padat $\left(\mathrm{m} \cdot \mathrm{s}^{-1}\right)$.

$\mathrm{D}_{e f f}$ : difusifitas efektif air dalam bahan padat $\left(\mathrm{m}^{2} \mathrm{~s}^{-1}\right)$.

Mounir \& Allaf (S. Mounir \& K. Allaf, 2009) mengasumsikan bahwa dengan mengabaikan pengaruh shrinkage yang mungkin terjadi, dan

$$
\frac{\partial \rho_{w}}{\partial t}=\left[D_{e f f} \frac{\partial^{2} \rho_{w}}{\partial r^{2}}\right]
$$

Difusivitas efektif $D_{\text {eff }}$ dianggap konstan karena suhu dianggap konstan dan struktur dari bahan dianggap homogen. Beberapa bentuk solusi matematik telah diusulkan, tergantung pada kondisi awal dan kondisi batas (A.S. Mujundar, 2006). Dalam studi ini

$$
M R=\frac{X-X_{e}}{X_{0}-X_{e}}=\sum_{i=1}^{\infty} A_{i} \exp \left(-q_{i}^{2} t\right)
$$

Dimana MR adalah Moisture Ratio, $\mathrm{X}$ menyatakan kandungan air basis kering pada saat $t, X_{e}$ menyatakan harga $\mathrm{X}$ pada saat kesetimbangan dengan menganggap bahwa difusivitas efektif konstan selama proses pengeringan, maka hukum kedua Fick untuk satu dimensi menjadi:

solusi yang dikemukakan oleh Crank digunakan, yang disesuaikan dengan geometri dari bahan (J. Crank, 1975). Dengan mengekspresikan kandungan air dalam bahan sebagai $\mathrm{X}$, maka persamaan bentuk (2) menjadi:

$$
M R=\frac{8}{\pi^{2}} \sum_{n=0}^{\infty} \frac{1}{(2 n+1)^{2}} \exp \left(-\frac{(2 n+1)^{2} \pi^{2} D_{e f f} t}{4 L_{0}^{2}}\right)
$$


Dimana $\mathrm{D}_{e f f}$ adalah difusivitas efektif $\left(\mathrm{m}^{2} / \mathrm{s}\right) ; \mathrm{L}_{0}$ adalah tebal bahan (m). Untuk waktu pengeringan yang panjang, persamaan (4) dapat disederhanakan dengan hanya

$$
\ln M R=\ln \frac{8}{\pi^{2}}-\frac{\pi^{2} D_{e f} t}{4 L_{0}^{2}}
$$

Difusivitas ditentukan dengan cara membuat plot data pengeringan yang diperoleh dari percobaan dalam bentuk

$$
\text { Slope }=\frac{\pi^{2} D_{e f f}}{4 L_{0}^{2}}
$$

Model pengeringan yang diekspresikan pada persamaan (5) disebut sebagai model teoritis karena diturunkan dari hukum kedua Fick tentang difusi. Model lain juga dikembangkan yang diturunkan dari hukum kedua Fick tentang difusi yang

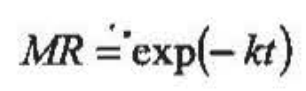

mengambil suku pertama (M. A. Tutuncu, and T. P. Labuza, 1996; Z. Pakowski \& A.S. Mujumdar , 2006). Jadi persamaan (2) dituliskan dalam bentuk logaritmik sebagai berikut:

In MR terhadap waktu $t$ dalam persamaan (3). Plot tersebut akan berupa garis lurus dengan slope:

telah disederhanakan, dan model ini disebut sebagai model semi-teoritis. Salah satu model semi-teoritis yang banyak digunakan adalah model Lewis yang formulasinya ditunjukkan pada persamaan (7), dimana $k$ adalah suatu konstanta. 


\section{BAHAN DAN METODE}

Buah apel segar diperoleh dari pasar lokal. Setelah dilakukan pengupasan kulitnya terlebih dahulu, apel kemudian dipotong-potong sehingga dihasilkan potongan apel yang berupa lapis tipis dengan tebal $5 \mathrm{~mm}$. Lapis tipis apel ini kemudian disusun di atas satu tray yang terbuat dari bahan stainless steell dengan luas $150 \mathrm{~mm} \times 150 \mathrm{~mm}$. Lapis tipis apel disusun sedemikian rupa sehingga sebagian besar permukaan tray terisi. Tray yang telah terisi kemudian dimasukkan di dalam pengering konveksi dan proses pengeringan dijalankan. Alat pengering konveksi pada prinsipnya terdiri dari fan sentrifugal untuk mensuplai aliran udara, pemanas listrik, dan electronic proportional controller. Sebelum delewatkan permukaan bahan, udara dipanaskan dengan pemanas listrik dan suhu udara dipertahankan konstan dengan menggunakan proportional controller. Selama percobaan pengeringan laju udara diukur dengan Anemometer. Pengeringan dilakukan pada suhu udara pengering $50{ }^{\circ} \mathrm{C}$ dengan laju $0,4167 \mathrm{~m} / \mathrm{s}$. Perubahan kandungan air bahan dari waktu ke waktu diukur dengan menimbang berat bahan selama pengeringan dan penimbangan dilakukan setiap 3 menit.

Dari data kandungan air dari waktu ke waktu, difusivitas efektif ditentukan dengan membuat plot ln MR terhadap $t$. Difusivitas efektif dihitung dari harga slope plot ini dengan menggunakan persamaan (6). Dari harga difusivitas efektif yang didapat, selanjutnya model solusi Crank yang disederhanakan (persamaan 5) digunakan untuk menghitung perubahan kandungan air terhadap waktu yang dinyatakan sebagai Moisture Ratio (MR). Selanjutnya Moisture Ratio juga dihitung dengan menggunakan model semi-teoritis Lewis dengan menggunakan persamaan (7), setelah terlebih dahulu mendapatkan nilai konstanta $k$ yang merupakan nilai slope dari plot In MR terhadap waktu t. Studi ini dilakukan untuk membandingkan MR yang dihasilkan dari perhitungan dengan menggunakan model teoritis solusi Crank dan perhitungan dengan menggunakan model semi-teoritis Lewis terhadap data percobaan.

\section{HASIL DAN DISKUSI}

Perubahan kadar air bahan selama proses pengeringan disajikan pada Gambar 1. Potongan tipis apel segar dengan kadar air awal $5,99 \mathrm{~kg}$ air $/ \mathrm{kg}$ padatan kering dikeringkan sampai kadar air kesetimbangan $0,23 \mathrm{~kg}$ air $/ \mathrm{kg}$ padatan kering yang memakan waktu 321 menit. 


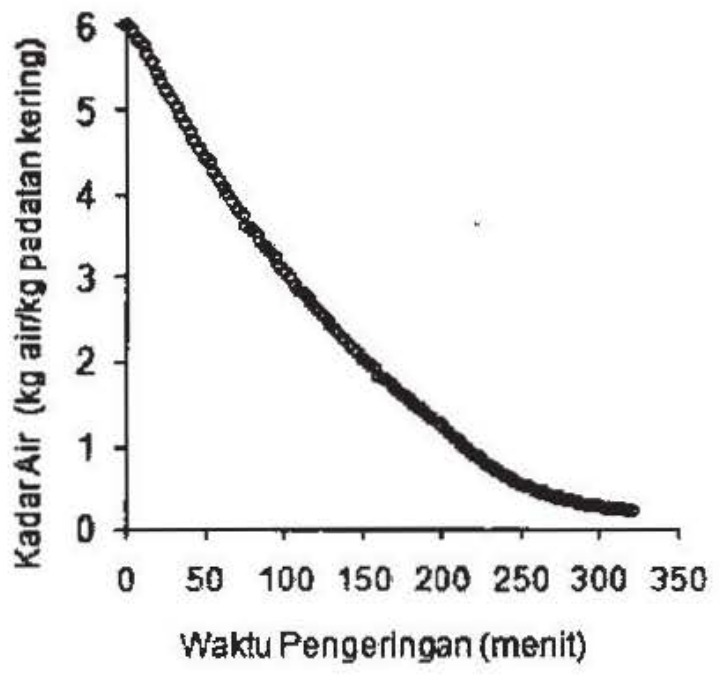

\section{Gambar 1. Kurva Pengeringan}

Dari kurva pengeringan tersebut kemudian dikontruksi plot in MR terhadap waktu t. Difusivitas efektif $\left(D_{\text {eff }}\right)$ diperoleh dengan melakukan regresi linier plot $\ln$ MR terhadap $t$ mengikuti persamaan (5) dan hasil regresi disajikan pada Gambar 2. Dari regresi ini didapatkan harga slope sebesar - 0,008 dan dengan menggunakan persamaan (6) didapatkan harga difusivitas efektif $D_{\text {eff }}=1,3523 \mathrm{x}$ $10^{-9} \mathrm{~m}^{2} / \mathrm{s}$. Harga $D_{\text {eff }}$ yang diperoleh ini selanjutnya digunakan untuk menghitung harga MR menurut model solusi Crank berdasarkan persamaan (5) dan hasilnya ditunjukkan dalam bentuk plot MR terhadap $\mathrm{t}$ yang disajikan pada Gambar 4.

Dari plot In MR terhadap t juga dilakukan regresi linier sesuai dengan model Lewis (persamaan7), regresi ini disajikan pada Gambar 3. Dari regresi ini didapatkan harga konstanta pada model Lewis $\mathrm{k}=-0,007$, yang merupakan harga slope dari persamaan regresi tersebut. Selanjutnya dengan nilai $\mathrm{k}$ tersebut dikontruksi plot MR terhadap $\mathrm{t}$ untuk model Lewis sesuai dengan persamaan (7) dan hasilnya disajikan pada Gambar 4. 


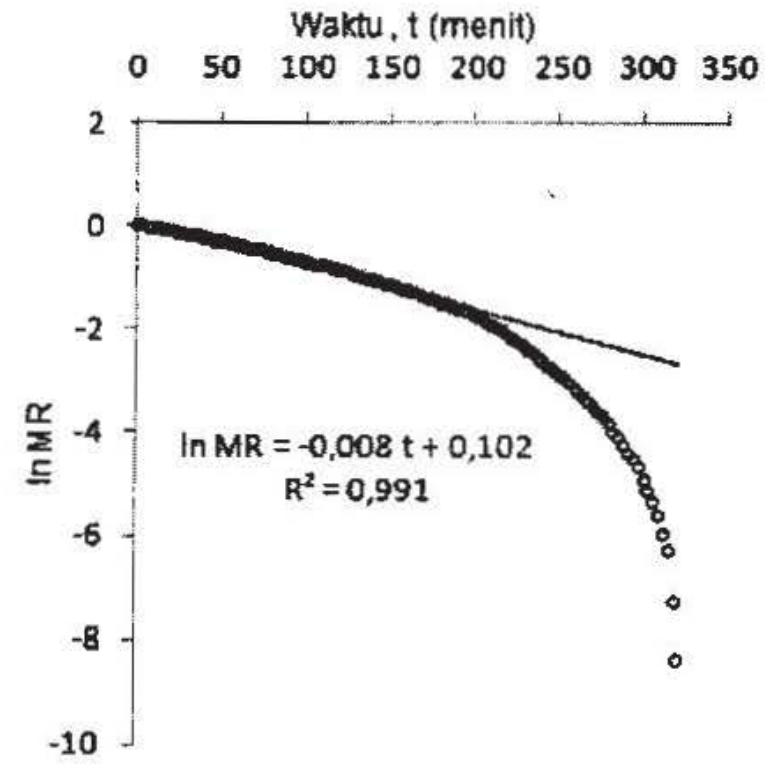

Gambar 2. Regresi untuk Model Solusi Crank

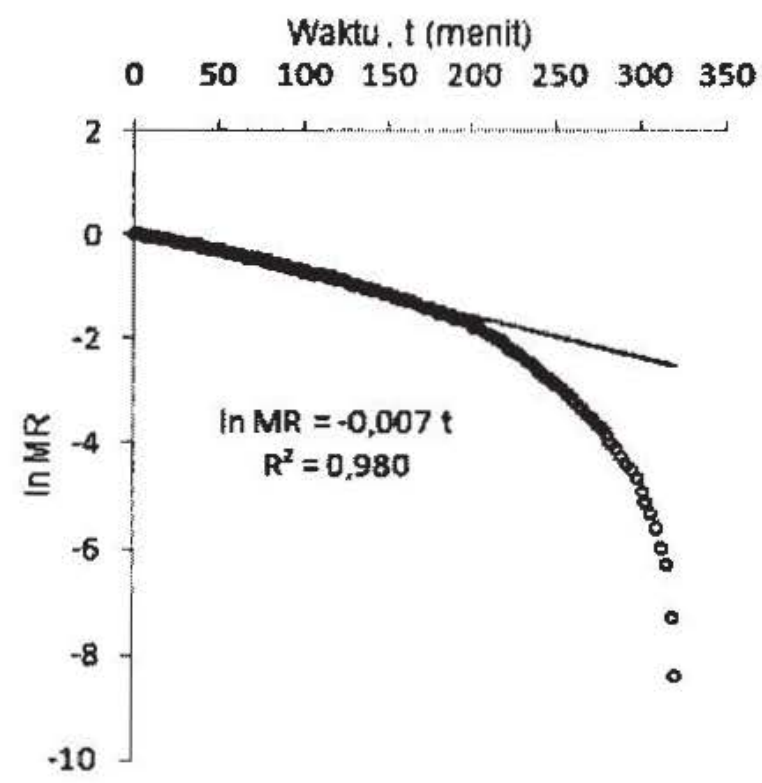

Gambar 3. Regresi untuk Model Lewis

Dari Gambar 3 dan Gambar 4 dapat dilihat bahwa regresi linier hanya dilakukan untuk data percobaan sampai dengan 200 menit. Hal ini dilakukan karena berdasarkan pengamatan selama percobaan, setelah 200 menit bahan mengalami deformasi, yaitu perubahan bentuk dari datar menjadi tidak datar/membentuk lengkungan. Akibat dari deformasi ini maka penguapan air dari bahan tidak hanya terjadi dari permukaan atas melainkan juga mulai terjadi dari sebagian permukaan sisi bawah. Semakin mendekati akhir pengeringan deformasi semakin besar. Akibatnya terjadi penyimpangan data 
percobaan dari model setelah 200 menit, dimana kalau mengikuti model plot $\ln$ MR terhadap $\mathrm{t}$ akan linier sampai akhir pengeringan. Karena model matematik dikembangkan untuk pengeringan lapis tipis dimana penguapan hanya terjadi dari satu sisi bahan, maka regresi linier banya dilakukan sampai 200 menit dimana bahan belum mengalami deformasi dan penguapan hanya terjadi melalui satu permukaan bahan.

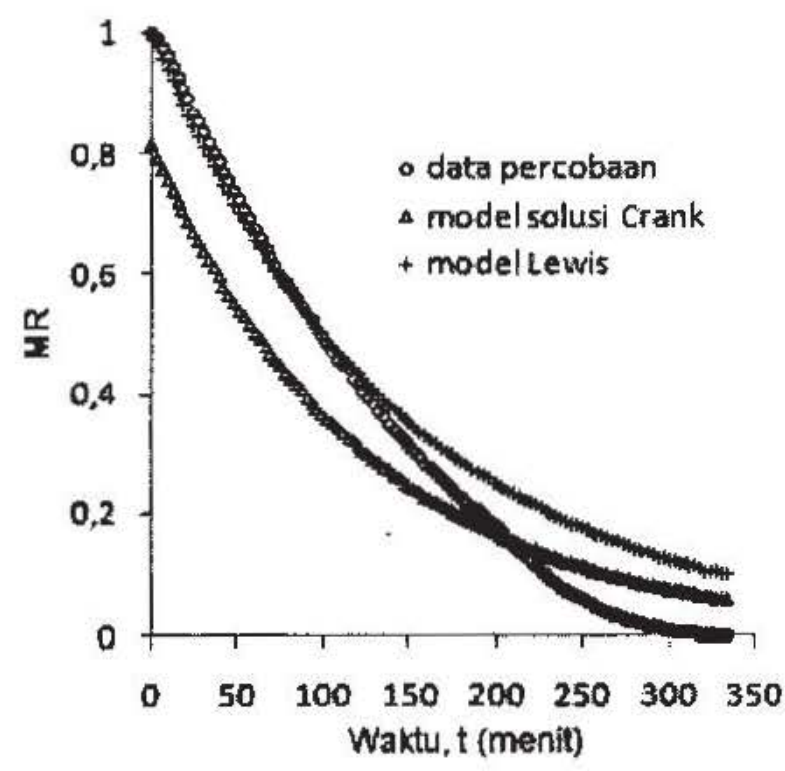

Gambar 4. Profil MR Percobaan dan Model

Dari Gambar 4 dapat dilihat bahwa mula-mula nilai MR yang dihitung dari model Lewis lebih kecil dari MR data percobaan, kemudian setelah memotong kurva MR data percobaan pada akhir proses pengeringan kurva MR model Lewis berada di atas kurva MR data percobaan. Hal ini menunjukkan bahwa model Lewis cukup relevan untuk memprediksi profil pengeringan untuk waktu pengeringan pendek. Penyimpangan yang terjadi setelah pengeringan berlangsung lama diakibatkan karena terjadinya deformasi bahan yang dikeringkan yang mengakibatkan terjadinya penguapan air dari sebagian sisi bawah dari bahan. Sementara model solusi Crank lebih sesuai untuk memprediksi kura pengeringan untuk waktu yang cukup lama. Disamping itu apapun kondisinya, intersep yang dihasilkan dari model solusi Crank akan selalu bernilai $\ln \left(8 / \pi^{2}\right)$, sehingga pasti akan terjadi deviasi model ini di awal periode pengeringan. $\mathrm{Hal}$ ini diperjelas dengan profil deviasi nilai MR yang dihitung dari model terhadap nilai MR data percobaan yang disajikan pada Gambar 5. Profil yang disajikan pada Gambar 5 menunjukkan bahwa model Lewis lebih sesuai digunakan untuk pengeringan dengan waktu pendek sedangkan model solusi Crank lebih sesuai digunakan untuk pengeringan dengan waktu yang panjang. Adapun penyimpangan yang besar dari kedua model terhadap data percobaan pada 
akhir masa pengeringan disebabkan karena terjadinya deformasi dari bahan yang dikeringkan.

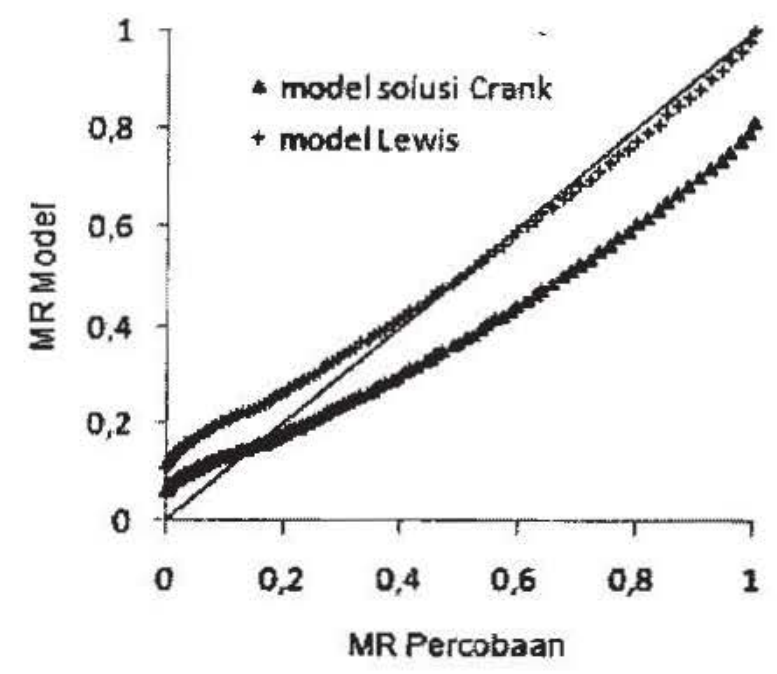

Gambar 5. Profil Deviasi MR Model terhadap MR Percobaan

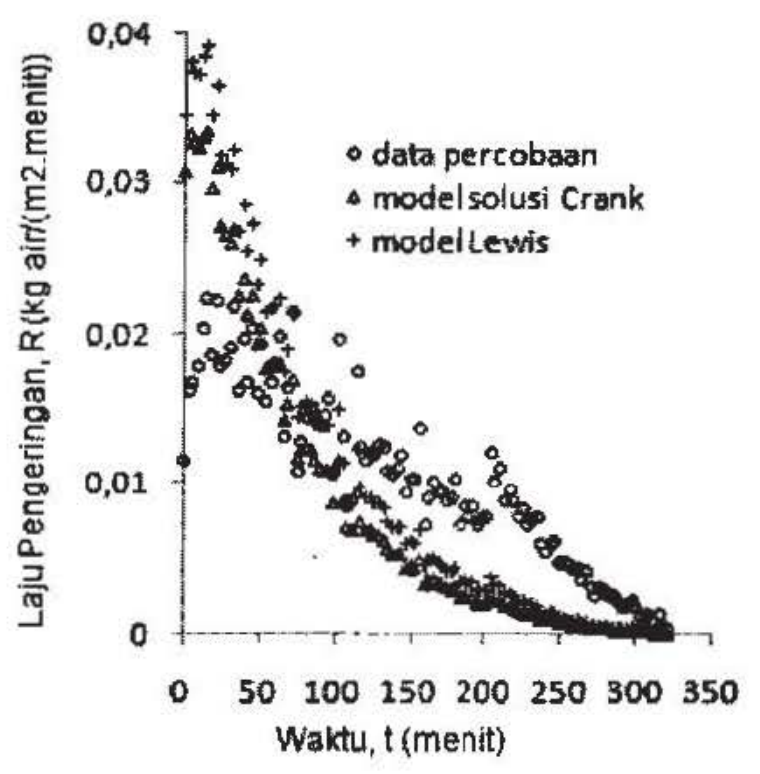

Gambar 6. Profil Laju Pengeringan

Pada Gambar 6 disajikan Profil laju pengeringan berdasarkan data percobaan dan juga yang dihitung dari kedua model. Dari Gambar 6 tersebut dapat dilihat bahwa secara keseluruhan laju pengeringan apel berada pada periode laju menurun, hal ini sesuai dengan profil pengeringan bahan-bahan biopolimer yang umumnya berlangsung dengan laju menurun. 
KESIMPULAN

Pada penelitian pengeringan lapis tipis apel ini dapat diambil kesimpulan bahwa model Lewis lebih sesuai digunakan untuk pengeringan dengan waktu pendek, sedangkan model solusi Crank lebih sesuai digunakan untuk pengeringan dengan waktu yang panjang. Disamping itu secara keseluruhan laju pengeringan apel berada pada periode laju menurun, yang hal ini sesuai dengan profil pengeringan bahan-bahan biopolimer yang umumnya beralangsung dengan laju menurun. 


\section{DAFTAR PUSTAKA}

A.S. Mujundar, 2006 . "Handbook of Industrial Drying". Third Edition, Edited by CRC Taylor \& Francis Group Press.

Atungulu, G., Y. Nishiyama and S. Koide, 2004. Electrode configuration and polarity effects on physiochemical properties of electric field treated apples post harvest. Biosystems Engineering, 87: 313-323:

Cohen, J.S. and T.C.S. Yang, 1995. Progress in food dehydration. Trends in Food Sci. and Technol., 6:20-25.

J. Crank, 1975. "The mathematics of diffusion", Oxford, England. Clarendon Press.

K. Allaf, 1982. "Transfer phenomena and industrial applications", Teaching book published by the Lebanese University, Faculty of Science.

Karathanos, V.T. and V.G. Belessiotis, 1999. Application of a thin layer equation to drying data fresh and semi-dried fruits. J. Agric. Eng. Res., 74: 355-361.

M. A. Tutuncu, and T. P. Labuza, 1996 . "Effect of geometry on the effective moisture transfer diffusion coefficient". Journal of Food Engineering, 30, pp. 433-447.

S. Mounir, 2007. "Etude de nouveaux procédés de fabrication de poudres par insertion de la technologie de détentes instantanée contrôlée DIC, dans les processus d'atomisation, de séchage/ texturation et de pulvérisation contrôlée sous vide de produits laitiers". PhD (Thèse de doctorat), University of La Rochelle.

S. Mounir \& K. Allaf, 2008. "Three-stage spray drying: new process involving instant controlled pressure drop (DIC)". Journal of Drying Technology, Vol. 26, No. 4, pp. 452-463.

S. Mounir \& K. Allaf, 2009. "Study and modeling of dehydration and rehydration kinetics within porous medium". Proceedings of AFSIA, Lyon (France), 14-15 May.

Wang, N. and J.G. Brennan, 1992. Effect of water binding on the drying behavior of potato. In A.S. Mujumdar (Ed.), Elsevier Science Publishers, 92: 1350-1359.

Wang, Z., J. Sun, X. Liao, F. Chen, G. Zhao, J. Wu and X. Hu, 2007. Mathematical modeling on hot air of thin layer apple pomace. J. Food Eng., 40: 39-46. 
Pemodelan matematik kandungan, Puguh Setyopratomo

Z. Pakowski \& A.S. Mujumdar, 2006. "Basic process calculations and simulations in drying". In HANDBOOK OF INDUSTRIAL DRYING, Third Edition, Edited by CRC Taylor \& Francis Group Press. 


\section{JURNAL ILMIAH}

\section{SAINS \& TEKNOLOGI}

Dini Kesuma

PENENTUAN NILAI PARAMETER LIPOFILITAS SENYAWA 4klorobenzoiltiourea dan UJI POTENSIASITERHADAPTIOPENTAL PADA MENCIT PUTIH (mus Musculus)

Indrajati Kohar, Rijanto Budiono, Sayekti Palupi, Kartini, Magdalena Kristiawan, Idfi Setyaningrum PENGARUH PERLAKUAN AWAL DIC PADA PENGERINGAN DAUN SALAM (Eugenia polyanta Wight, Walp) TERHADAP EFISIENSI EKSTRAKSI DAN KECUKUPAN KANDUNGAN SENYAWA FENOL TOTAL (Phenol Content)

Stephanus Eko Wahxudi

EFHECTIVE USE OF INFORMATION TECHNOLOGY TO ENHANCE JOB SEEKING PROCESSINEAST JAVA INDONESLA THROUGHONLINEJOB SERVICE CENTER

Puguhsetyopratomo

PEMODELAN MATEMATIK KANDUNGANAIR PADA PENGERINGANAPEL

Amelia Lorensia, Azie Hubeis, Widyari, Hary Bagio

STUDI PENGOBATAN YANG DIPERLUKAN PADA PASIEN SIROSIS VANG MENIALANI RAWAT INAP DI RUMAH SAKIT

Susana Limanto, Ellysa Tjandra

PEMBUATAN SISTEM INFORMASI TANAMAN OBAT YANG IMPLEMENTATIF

Sains \& Teknologi = Vol. 4 = No. 1 - Hal. 1-76 = Desember, 2010 


\title{
JURNAL ILMIAH \\ SAINS \& TEKNOLOGI \\ ISSN 02161540
}

Terbit dua kali setahun pada bulan Juni dan Desember. Berisi tulisan yang berasal dari hasil penelitian, kajian atau karya ilmiah di bidang Sains dan Teknologi.

Ketua Penyunting

Ketua Lembaga Penelitian dan Pengabdian Kepada Masyarakat

\author{
Penyunting Pelaksana \\ Benny Lianto \\ Nani Parfati \\ Andreas Alfianto
}

Straf Pelaksana

Tang Hamidy, Hadi Krisbiyanto, Sukono

Penerbir

Lembaga Penelitian dan Pengabdian Kepada Masyarakat

Universitas Surabaya

Alamat Penerbit/Redaksi

Gedung Perpustakaan LtIV, Universitas Surabaya

Jalan Raya Kalinungkut, Surabaya, 60293

Telp. (031) 2981360, 2981365

Fax. (031) 2981373

Website : http://ppmubaya.acid

Email : lppm@ubayaacid

Jumal Ilmiah Sains dan Teknologi pernah terbit dengan nama Unitas (pertama kali terbit tahun 1992) oleh Lembaga Penelitian Universitas Surabaya. 


\section{JURNAL ILMIAH \\ SAINS \& TEKNOLOGI}

ISSN 0216-1540

Volume 4 Nomor 1, Desember 2010

Halaman 1.76

\section{Dini Kesuma}

PENENTUAN NILAI PARAMETER LIPOFILITAS SENYAWA 4klorobenzoiltiourea dan UII POTENSIASI TERHADAPTIOPENTAL PADA MENCIT PUTIH (mus Musculus)

(hal: 1-17)

Indrajati Kohar, Rijanto Budiono, Sayekti Palupi, Kartini, Magdalena Kristiawan, Idfi Setyaningrum PENGARUH PERLAKUAN AWAL DIC PADA PENGERINGAN DAUN SALAM (Eugenia polyanta Wight, Walp) TERHADAP EFISIENSI EKSTRAKSI DAN KECUKUPAN

KANDUNGAN SENYAWA FENOL TOTAL (Phenol Content)

(hal: 18-28)

Stephanus Eko Wahyudi

EFFECTIVE USE OF INFORMATION TECHNOLOGY TO ENHANCE JOB SEEKING PROCESS IN EAST JAVA INDONESIA THROUGH ONLINE JOB SERVICE CENIER (hal: 2944)

Puguh Setyopratomo

PEMODELAN MATEMATIK KANDUNGAN AIR PADA PENGERINGAN APEL (hal: 45-56)

Amelia Lorensia, Aziz Hubeis, Widyati, Hary Bagijo

STUDI PENGOBATAN YANG DIPERLUKAN PADA PASIEN SIROSIS YANG MENJALANI RAẄAT INAP DI RUMAH SAKIT

(hal: 57-69)

Susana Limanto, Elysa Tjandra PEMBUATAN SISTEM INFORMASI TANAMAN OBAT YANG IMPLEMENTATIF (hal: 70.76) 